\title{
Axial Compression Behaviour of Hybrid Double-Skin Tubular Columns Filled with Rubcrete
}

\author{
Osama Youssf ${ }^{1,2, *(\mathbb{D})}$, Reza Hassanli ${ }^{1}(\mathbb{D})$, Julie E. Mills ${ }^{1}(\mathbb{D})$ and Yan Zhuge ${ }^{1}(\mathbb{D}$ \\ 1 School of Natural and Built Environments, University of South Australia, Adelaide, SA 5095, Australia; \\ Reza.Hassanli@unisa.edu.au (R.H.); Julie.Mills@unisa.edu.au (J.E.M.); Yan.Zhuge@unisa.edu.au (Y.Z.) \\ 2 Structural Engineering Department, Mansoura University, Mansoura 35516, Egypt \\ * Correspondence: Osama.Youssf@mymail.unisa.edu.au; Tel.: +61-470-655-266
}

Received: 16 May 2019; Accepted: 14 June 2019; Published: 19 June 2019

\begin{abstract}
Double-skin tubular columns (DSTCs) have become a competitive candidate for column members due to their important advantages compared with conventional reinforced concrete columns, including their better weight-to-strength ratio and ease of construction. Using Rubcrete in hybrid DSTCs is of great interest due to the potential of this system to overcome the Rubcrete material deficiencies and to add more ductility, toughness, seismic resistance, confinement effectiveness, and environmentally-friendly features to that structural system compared to conventional concrete. In this paper, hybrid DSTCs made out of Rubcrete, sandwiched between a fibre reinforced polymer (FRP) tube and a steel tube, were tested. The examined variables were concrete sand or stone replacement ratio ( $0 \%$ and $20 \%)$, FRP wall thickness (1- and 2-layers), steel wall thickness ( $3.2 \mathrm{~mm}$ and $4.5 \mathrm{~mm}$ ), void ratio (50\% and $76 \%$ ), and void shape (circular or square). The axial and lateral stress-strain responses were monitored, measured, and compared. According to this investigation, using Rubcrete in hybrid DSTCs can enhance the axial and hoop strain capacities, especially with fine rubber particles. It was also observed that the adverse influence of using rubber on column ultimate capacity was much lower in DSTC specimens, compared with that of unconfined Rubcrete columns. Therefore, using Rubcrete with fine rubber particles is recommended in DSTC structural columns.
\end{abstract}

Keywords: rubberized concrete; double-skin columns; hybrid columns; tubular columns; FRP confinement

\section{Introduction}

The use of motor vehicles is now universal around the world, which has resulted in immense numbers of used tyres being dumped into landfill. Across the world, over one billion end-of-life tyres are disposed of into landfill each year, and it is estimated that this will increase by half a billion each year in 2030 [1]. Of this amount, Australia contributes forty nine million tyres annually, of which only $16 \%$ are recycled $[2,3]$. The other $84 \%$ ends up in landfill where these tyres have been known to catch uncontrolled fire. The disposed tyres are also unsuitable for burial due to their poor degradation [4]. Hence, it is important to find an appropriate application to use tyre waste instead of sending them to landfill. A significant body of research has been exploring processes in which rubber tyres can be utilized. One current prospect is the consumption of the rubber waste in construction materials like concrete, resulting in a product known as Rubcrete. The addition of rubber to the concrete mixture reduces the volume of aggregate required, which conserves natural resources whilst reducing the tyre waste in landfill [5]. In addition, rubber in concrete has less chance of catching fire as it is embedded in the concrete matrix. It has been reported that compared to conventional concrete, Rubcrete has lower tensile and compressive strength as well as modulus of elasticity [6,7]. On the other hand, Rubcrete can improve other properties of concrete including ductility, durability, energy dissipation, damping 
ratio, and impact resistance [8-10]. As a result of its better dilatancy performance, it has been reported in previous studies that confining of Rubcrete by fibre reinforced polymer (FRP) is more effective compared to traditional concrete [11-14].

Double skin tubular columns (DSTCs) consist of two tubular shells sandwiching concrete in between them and leaving the centre hollow [15]. Hybrid DSTC is a form of DSTC that has two tubes, an internal steel tube, and an external FRP tube; between which concrete is cast. The benefit of combining the three materials is to make a lightweight concrete column with high performance. This structural system can accommodate a variety of external and internal shapes for both tubes (e.g., circular, rectangular, elliptical, etc.). Hybrid DSTCs have become a good candidate for structural columns due to their important advantages over conventional reinforced concrete columns, including their high strength-to-weight ratio, ease of construction in situ or precast, easy connection to other members (due to the presence of an inner steel tube and the concrete), less periodical maintenance required, and economical construction features (in which the two tubes act as stay in place formwork) $[16,17]$. Because of the heat-sink effect of the concrete, the DSTC system has low thermal conductivity. This helps to reduce the rise of temperature [18].

To date, some researchers have investigated the behaviour of hybrid DSTCs made out of normal strength concrete and high strength concrete under different loading schemes. Yu et al. [16] showed a ductile behaviour of hybrid DSTCs under different types of cyclic loading schemes. Yu and Teng [17] reported that the ultimate axial stresses of square DSTCs were similar to those of FRP-confined solid square columns. Cavill and Yu's [19] test results indicated that the load enhancement was more significant for DSTCs with a thicker FRP/steel tube or a larger corner radius. Yu et al. in [20] showed that the strain distribution in DSTCs subjected to eccentric compression was similar to that of solid FRP-confined columns, except for the tension strains in the steel tube after yielding. Ozbakkaloglu [21] showed that the diameter of the inner steel tube significantly affected the behaviour of both hollow and filled (with concrete) DSTCs. An increase in the steel tube diameter caused a decrease in the second branch slope of the stress-strain curves of hollow DSTCs and an increase in that of filled DSTCs. Abdelkarim and ElGawady [15] showed that the DSTC behaviour is controlled by the tubes' stiffness. Yao et al. [22] observed an increase in the ultimate axial strain with the load eccentricity increase. A larger load eccentricity resulted in lower axial load capacity and larger deformability. Thicker FRP tubes resulted in larger axial load capacity and deformability. Dong and Ho [23] showed that for $56 \%$ and $72 \%$ diameter void ratios, the external steel rings enhanced the strength by $11.5 \%$ and $9.5 \%$, respectively, and stiffness by $24.7 \%$ and $31.2 \%$, respectively. Wen et al. [24] studied the size effect of DSTCs on the axial compression performance and concluded that the influence of the specimen size on the stress-strain behaviour was insignificant. Teng et al. [25] applied the idea of hybrid DSTC in beams by shifting the inner steel tube toward the tension side of the beam and showed a very ductile behaviour of the beams, where the FRP tube enhanced the beam structural behaviour by providing both confinement and additional shear resistance. Wang et al. [26] found that the FRP jacket can significantly enhance the load carrying capacity of columns. In addition, they reported that the diameter void ratio had negligible influence on the axial stress-strain behaviour of the FRP-confined columns. Mathew et al. [27] found that the lateral strength and ductility of the DSTCs were 79\% and $12.8 \%$ higher, respectively, than those of a steel-confined solid column. Zhang et al. [28] found that by increasing the concrete strength and FRP thickness, the column lateral strength increased. It was also reported that by increasing the axial load ratio, the column lateral deformation capacity decreases. Welded corrugated plates were also employed as inner and/or outer tubes for DSTCs filled with conventional concrete [29-31].

From the literature review presented above, it is clear that although conventional concrete with different strengths has been utilized in hybrid FRP-concrete-steel structural systems under different loading conditions, Rubcrete is yet to be involved in this structural system. Compared with the FRP-confined conventional concrete, FRP-confined Rubcrete is more effective [5,12,32], hence, using Rubcrete in DSTCs can potentially improve the column's strength, damping, ductility, energy 
dissipation, and durability. This can introduce a new environmentally-friendly application to recycle tyre waste without compromising the structural behaviour of columns. In this investigation, the effect of using Rubcrete rather than conventional concrete in DSTCs was investigated through a series of experimental measurements. The interaction of other parameters including the inner steel wall thicknesses, void ratios, and void shapes with infilled Rubcrete were investigated and compared with those of conventional concrete. The axial and hoop stress-strain behaviour as well as the volumetric response of the tested columns were measured and compared. This study shows the first use of Rubcrete in DSTC structures, and highlights a new potential application for Rubcrete.

\section{Experimental Program}

\subsection{Materials}

In all concrete mixes, general purpose cement (with a specific gravity of 3.15) was used. For the coarse and fine aggregates, $14 \mathrm{~mm}$ dolomite stone and $5 \mathrm{~mm}$ concrete sand were used, respectively. Both coarse and fine rubber particles were used in this research, which partially replaced the same volume of stone and sand, respectively. The fine and coarse rubber had particle sizes of 1.18-2.36 mm and 9.5-16.0 mm, respectively. Figure 1 displays the sieve analysis of all of the concrete aggregates. Dolomite stone, sand, fine rubber and coarse rubber had a specific gravity of 2.72, 2.65, 0.97 and 0.97, fineness modulus of 7.89, 2.20, 4.85, and 7.52, and unit weight of 1590, 1420, 530 and 590, respectively. To achieve a suitable workability (a slump of $130 \mathrm{~mm}$ to $150 \mathrm{~mm}$ ), superplasticizer (Polycarboxylic ether type) was added to the mixes.

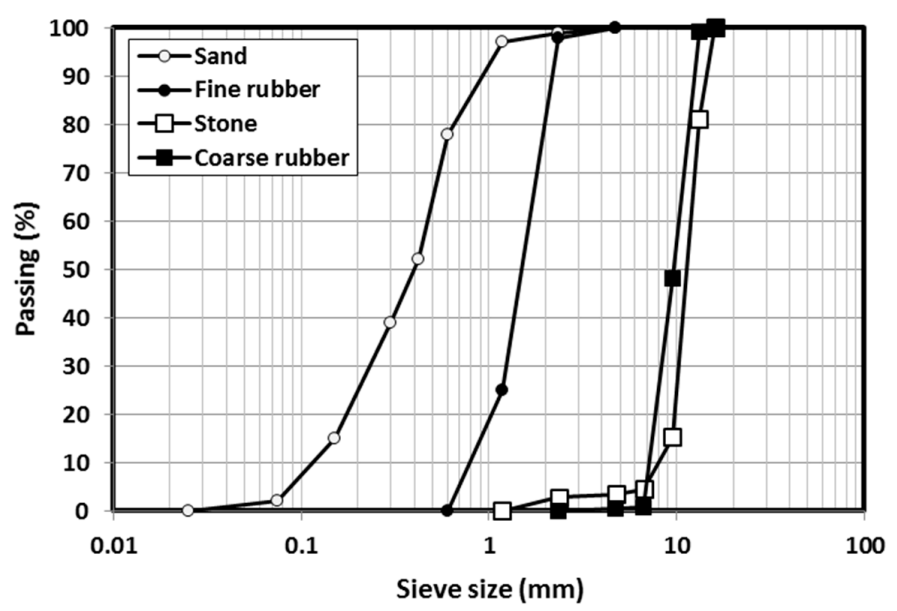

Figure 1. Sieve analysis.

To form the outer FRP-confinement tube, unidirectional sheets of carbon FRP $0.129 \mathrm{~mm}$ thickness and two-part epoxy resin (Sikadure 330) were employed. The ultimate strength, rupture strain, modulus of elasticity, and density, for the carbon FRP sheets were $4000 \mathrm{MPa}, 1.7 \%, 230 \mathrm{GPa}$, and $1820 \mathrm{~kg} / \mathrm{m}^{3}$, respectively and for epoxy resin were $30 \mathrm{MPa}, 0.9 \%, 4.5 \mathrm{GPa}$, and $1300 \mathrm{~kg} / \mathrm{m}^{3}$, respectively. Circular and square steel tubes with different wall thicknesses and diameters/dimensions were used to form the inner tube for the hybrid DSTCs. The nominal yield strength, ultimate strength, and Young's modulus of the steel tubes provided by the manufacturer were $350 \mathrm{MPa}, 430 \mathrm{MPa}$, and $200 \mathrm{GPa}$, respectively.

\subsection{Proportions of Concrete Mixtures}

A conventional concrete mixture which was considered as the control one, was designed for a target compressive strength of $55 \mathrm{MPa}$. Constant water to cement (W/C) ratio, superplasticizer (SP) dosage, and cement amount, were used in all mixtures in this study. The ratio of fine to coarse aggregate for the control mix was 1.0 to 1.2 by weight. Three mixes were used, including one conventional concrete and two Rubcrete mixes. For the Rubcrete mixes, either sand or gravel were partially replaced 
with similar size rubber aggregates. Rubber was used as received, without pre-treatment. Table 1 presents the proportions of concrete mixtures used. The mixture label used starts with the letter " $R$ ", which is followed by 0 or 20 , which represents the rubber content, defined as the $\%$ of sand or stone volume replaced by rubber. This is followed by the letter " $\mathrm{F}$ " or " $\mathrm{C}$ " indicating whether fine aggregate or coarse aggregate was replaced by rubber, respectively.

Table 1. Mix proportions and physical properties.

\begin{tabular}{|c|c|c|c|c|c|c|c|c|c|c|c|}
\hline \multirow{3}{*}{$\begin{array}{c}\text { Mix } \\
\text { Label }\end{array}$} & \multirow{3}{*}{$\begin{array}{c}\text { Rubber } \\
\text { Content } \\
(\%)\end{array}$} & \multicolumn{7}{|c|}{ Quantities $\left(\mathrm{kg} / \mathrm{m}^{3}\right)$} & \multirow{3}{*}{$\begin{array}{l}\text { Strength } \\
\text { (MPa) }\end{array}$} & \multirow{3}{*}{$\begin{array}{l}\text { Slump } \\
(\mathrm{mm})\end{array}$} & \multirow{3}{*}{$\begin{array}{c}\text { Air } \\
\text { Content } \\
(\%)\end{array}$} \\
\hline & & \multirow{2}{*}{ Cement } & \multirow{2}{*}{ Water } & \multirow{2}{*}{ Dolomite } & \multirow{2}{*}{ Sand } & \multicolumn{2}{|c|}{ Rubber } & \multirow{2}{*}{ SP } & & & \\
\hline & & & & & & Fine & Coarse & & & & \\
\hline R0 & 0 & 400 & 200 & 985 & 817 & 0.0 & 0.0 & 2.37 & 57.8 & 145 & 2.30 \\
\hline R20F & 20 & 400 & 200 & 985 & 654 & 59.8 & 0.0 & 2.37 & 39.6 & 220 & 2.17 \\
\hline R20C & 20 & 400 & 200 & 788 & 817 & 0.0 & 70.3 & 2.37 & 31.3 & 165 & 1.73 \\
\hline
\end{tabular}

\subsection{Specimen Preparation and Variables}

Table 2 presents the details of the specimens prepared in this study. Twelve circular DSTC specimens (DS1-DS12) with $150 \mathrm{~mm}$ outer diameter and $300 \mathrm{~mm}$ height were prepared with internal steel tube and external FRP tube sandwiching concrete in between. The variables in these twelve specimens were the rubber content of 0 and $20 \%$ as a replacement of sand or stone volume, the FRP thickness of 1 and 2-layers, the inner steel tube thickness of $3.2 \mathrm{~mm}$ and $4.5 \mathrm{~mm}$, the diameter void ratio of $51 \%$ and $66 \%$, and the void shape of circular and square. The diameter void ratio is defined as the ratio between the diameter of the central circular void created and the outer diameter of the specimen. The void shape effect was measured by using a square steel tube with $65 \times 65 \mathrm{~mm}$ dimensions and $3.0 \mathrm{~mm}$ thickness that had a similar void ratio and net cross-sectional area (similar axial capacity) to those of a steel tube with a circular shape and a $76.1 \mathrm{~mm}$ diameter and $3.2 \mathrm{~mm}$ thickness. The void ratio effect was measured by using inner steel tubes with similar cross-sectional area (similar axial capacity) but different diameters $(76.1 \mathrm{~mm}$ and $99.0 \mathrm{~mm}$ ) and different wall thickness $(3.2 \mathrm{~mm}$ and $2.5 \mathrm{~mm}$, respectively). Figure 2 presents the dimension details of the tested specimens. From each mix, six standard concrete cylinders having a diameter $\times$ height of $100 \times 200 \mathrm{~mm}$ were prepared and tested after 28 days for compressive strength, according to the Australian Standard (AS) 1012.14 [33].

Manufacturing of the DSTC specimens was carried out using $150 \mathrm{~mm} \times 300 \mathrm{~mm}$ cylindrical steel moulds with wooden bases by centralizing the inner steel tubes using a steel disk of $20 \mathrm{~mm}$ thickness bolted to the wooden base with the same inner diameter of the steel tube with enough clearance. The inner steel tubes were $350 \mathrm{~mm}$ high, which was $50 \mathrm{~mm}$ higher than the steel mould for ease of centralizing. The steel moulds were then positioned parallel to the inner tube to form the specimen before wrapping the FRP as the outer skin. Additional steel angles were placed at the top of the specimens before concrete pouring to maintain the central positioning of the inner tube while filling and compacting concrete. All concrete cylindrical specimens were cured in a water bath at a temperature of $23 \pm 2{ }^{\circ} \mathrm{C}$ for 7 days, according to Australian code, AS 1012.8.1 [34]. The extra $50 \mathrm{~mm}$ of the steel tubes was then trimmed using a mechanical steel saw and both top and bottom of the specimens were ground using a concrete grinder. All specimens were then left to air dry before wrapping them with the FRP outer skin. Figure 3a,b shows the details of specimen preparation. The FRP fibres were uni-directional and oriented in the hoop direction with overlap of $30 \%$ of the column circumference. The wrapped specimens with FRP were cured for 7 days at room temperature before testing. The FRP wrapping procedures around the columns are shown in Figure 3c. 

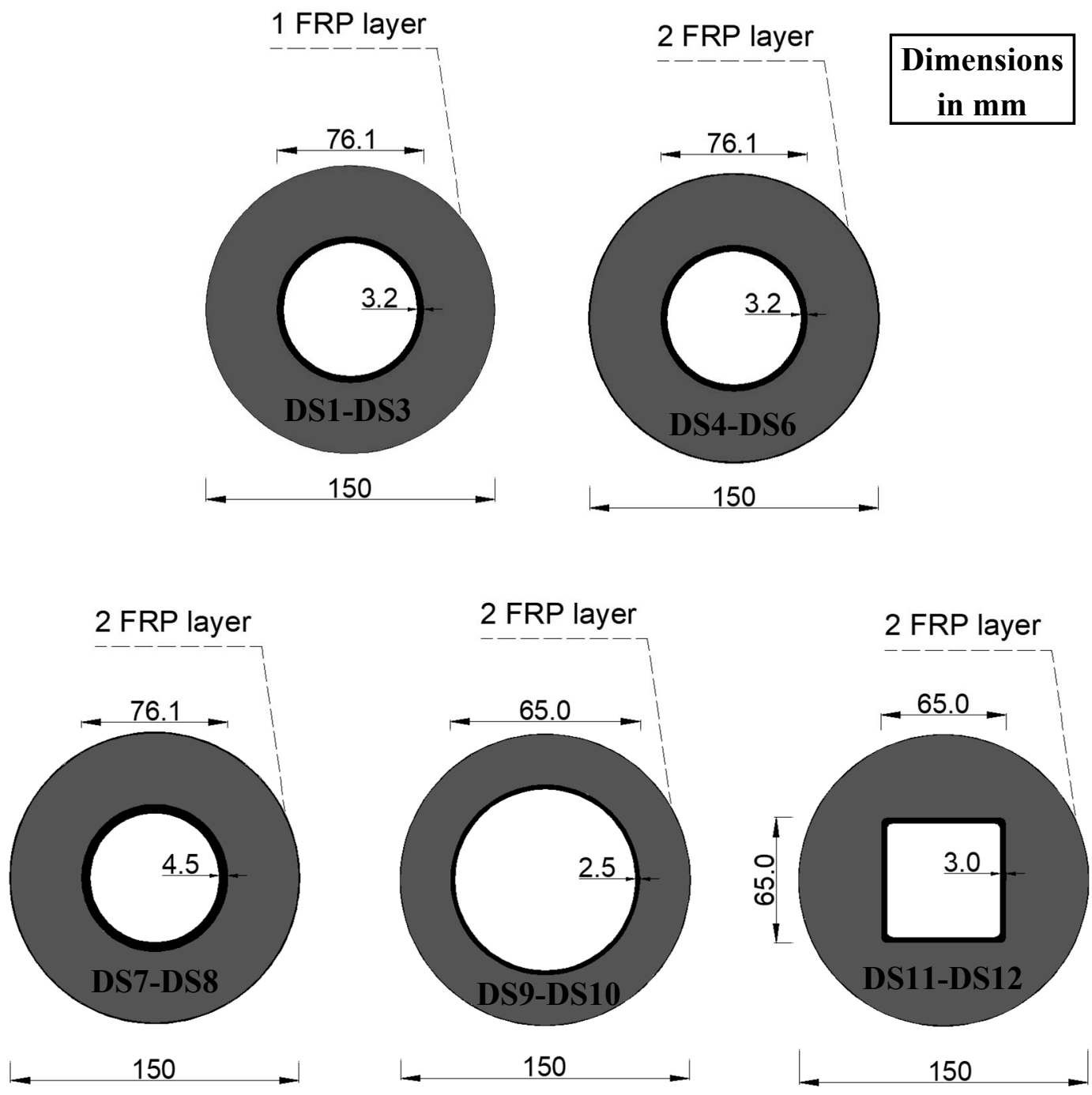

Figure 2. Cross-sectional dimensions of test columns.
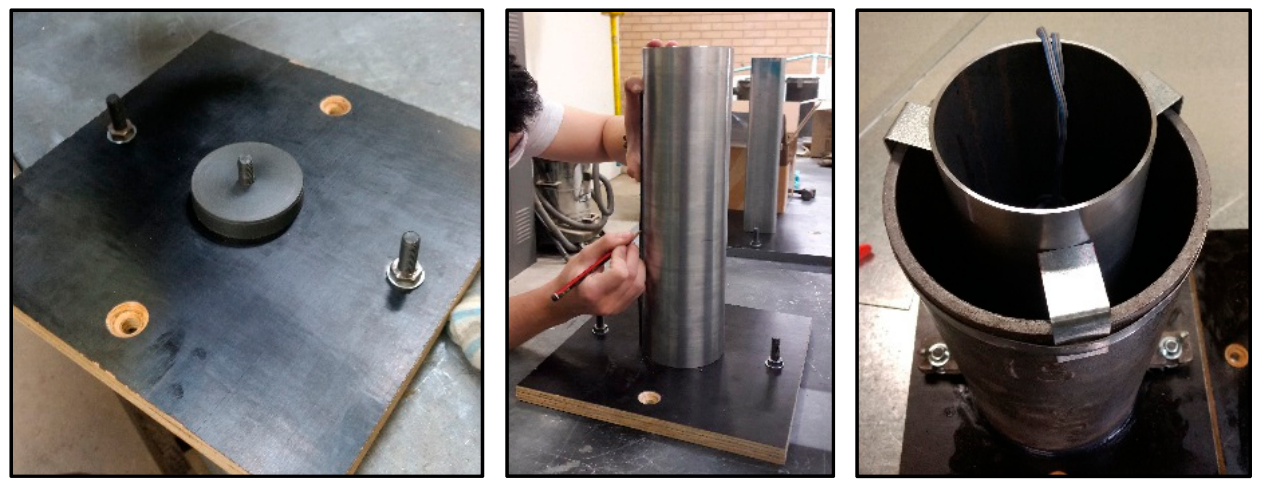

(a)

Figure 3. Cont. 


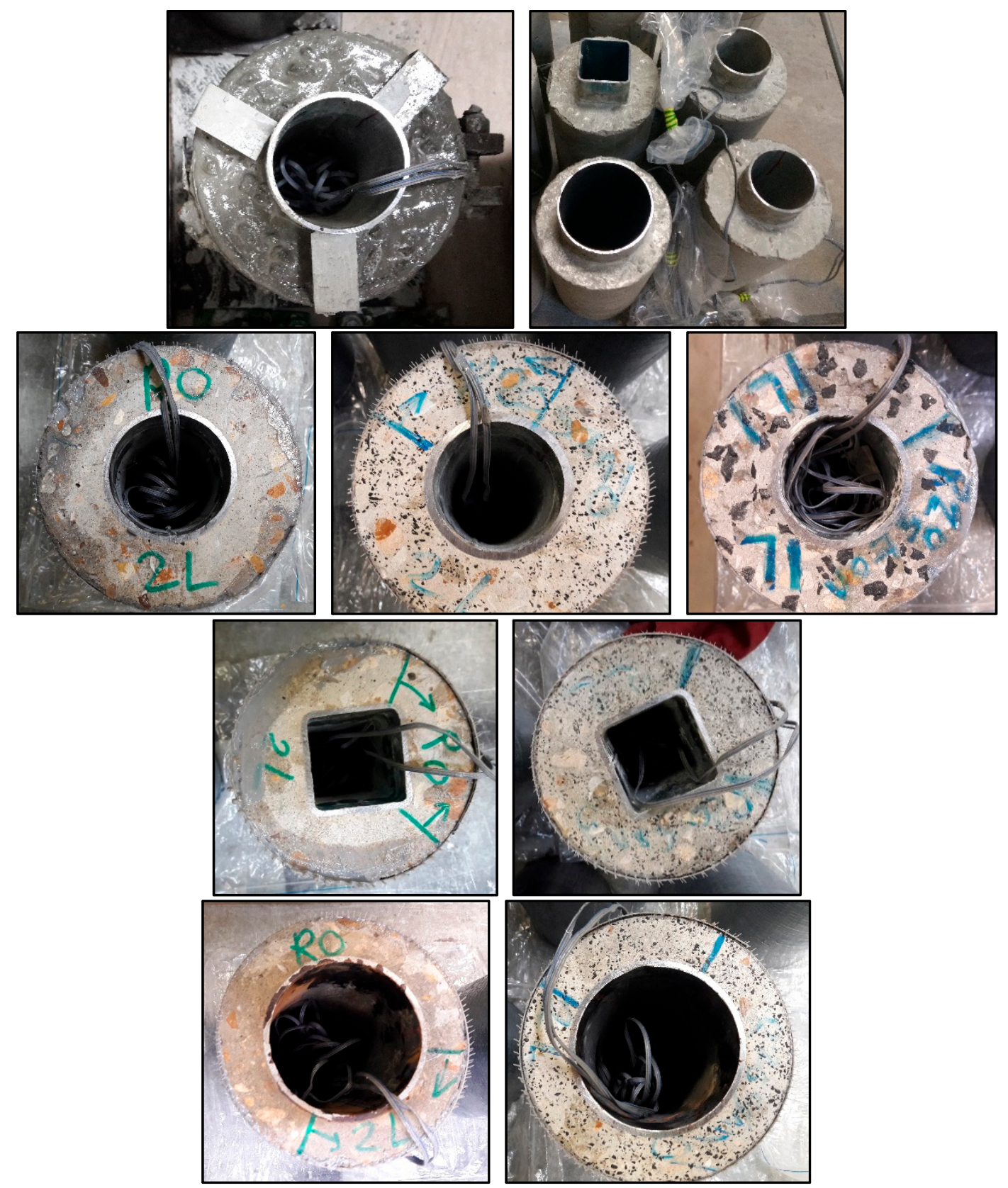

(b)
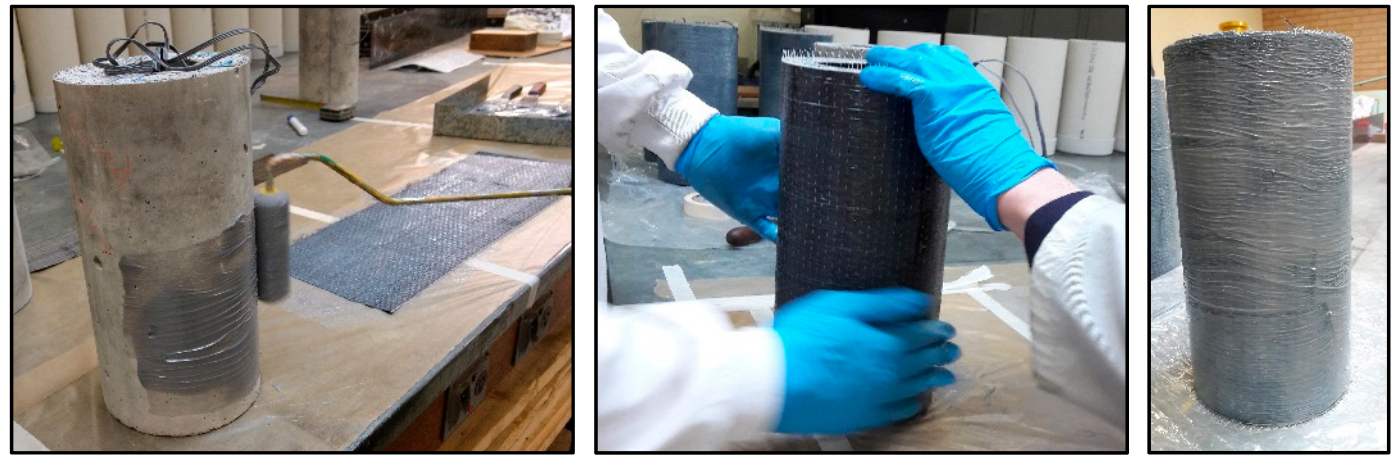

(c)

Figure 3. Specimen preparation: (a) Inner steel tube and moulds, (b) concrete casting and end grinding, and (c) FRP-wrapping. 
Table 2. Details of specimens tested in this study.

\begin{tabular}{|c|c|c|c|c|c|c|}
\hline \multirow{2}{*}{$\begin{array}{l}\text { Specimen } \\
\text { Code }\end{array}$} & \multirow{2}{*}{$\begin{array}{l}\text { Concrete } \\
\text { Mix }\end{array}$} & \multicolumn{2}{|c|}{ Inner Void } & \multirow{2}{*}{$\begin{array}{c}\text { FRP } \\
\text { Thickness } \\
\text { (Layers) }\end{array}$} & \multicolumn{2}{|c|}{ Steel Tube } \\
\hline & & Shape (mm) & $\begin{array}{c}\text { Diameter Void } \\
\text { Ratio (\%) }\end{array}$ & & $\begin{array}{l}\text { Thickness } \\
\text { (mm) }\end{array}$ & $\begin{array}{c}\text { Cross-Sectional } \\
\text { Area }\left(\mathrm{mm}^{2}\right)\end{array}$ \\
\hline DS1 & R0 & $\begin{array}{c}\text { Circular } \\
\text { (76.1 diameter) }\end{array}$ & 51 & 1 & 3.2 & 732.8 \\
\hline DS2 & R20F & $\begin{array}{c}\text { Circular } \\
\text { (76.1 diameter) }\end{array}$ & 51 & 1 & 3.2 & 732.8 \\
\hline DS3 & R20C & $\begin{array}{c}\text { Circular } \\
\text { (76.1 diameter) }\end{array}$ & 51 & 1 & 3.2 & 732.8 \\
\hline DS4 & R0 & $\begin{array}{c}\text { Circular } \\
\text { (76.1 diameter) }\end{array}$ & 51 & 2 & 3.2 & 732.8 \\
\hline DS5 & $\mathrm{R} 20 \mathrm{~F}$ & $\begin{array}{c}\text { Circular } \\
\text { (76.1 diameter) }\end{array}$ & 51 & 2 & 3.2 & 732.8 \\
\hline DS6 & R20C & $\begin{array}{c}\text { Circular } \\
\text { (76.1 diameter) }\end{array}$ & 51 & 2 & 3.2 & 732.8 \\
\hline DS7 & R0 & $\begin{array}{c}\text { Circular } \\
\text { (76.1 diameter) }\end{array}$ & 51 & 2 & 4.5 & 1012.2 \\
\hline DS8 & $\mathrm{R} 20 \mathrm{~F}$ & $\begin{array}{c}\text { Circular } \\
\text { (76.1 diameter) }\end{array}$ & 51 & 2 & 4.5 & 1012.2 \\
\hline DS9 & R0 & $\begin{array}{c}\text { Circular } \\
\text { (99.0 diameter) }\end{array}$ & 66 & 2 & 2.5 & 757.9 \\
\hline DS10 & $\mathrm{R} 20 \mathrm{~F}$ & $\begin{array}{c}\text { Circular } \\
\text { (99.0 diameter) }\end{array}$ & 66 & 2 & 2.5 & 757.9 \\
\hline DS11 & R0 & $\begin{array}{c}\text { Square } \\
(65 \times 65)\end{array}$ & 51 & 2 & 3.0 & 744.0 \\
\hline DS12 & $\mathrm{R} 20 \mathrm{~F}$ & $\begin{array}{l}\text { Square } \\
(65 \times 65)\end{array}$ & 51 & 2 & 3.0 & 744.0 \\
\hline
\end{tabular}

\subsection{Instrumentation and Test Setups}

A range of instrumentation was employed to record the specimens' behaviours. Displacement control with $0.003 \mathrm{~mm} / \mathrm{s}$ loading rate was used for specimen loading until failure occurred. Two linear variable displacement transducers (LVDTs) $180^{\circ}$ apart were used to capture the axial strains between the ends of the columns. Hoop strains were recorded for both the inner-skin steel tube and outer-skin FRP tube. For the steel and FRP tube, electrical strain gauges with a length of $10 \mathrm{~mm}$ and $60 \mathrm{~mm}$ were used, and were located at each specimen's mid-height. For both steel and FRP tubes, the strain gauges were bonded parallel to each other (the steel strain gauge and FRP strain gauge were attached at the same side of the specimen) and positioned outside the overlapping zone of the FRP tube. The locations of the LVDTs and strain gauges can be seen in Figure 4. Computer software (LABVIEW 8.6) was used to record the data. Traditional compression tests were also carried out on standard $100 \times 200 \mathrm{~mm}$ concrete cylinders. 


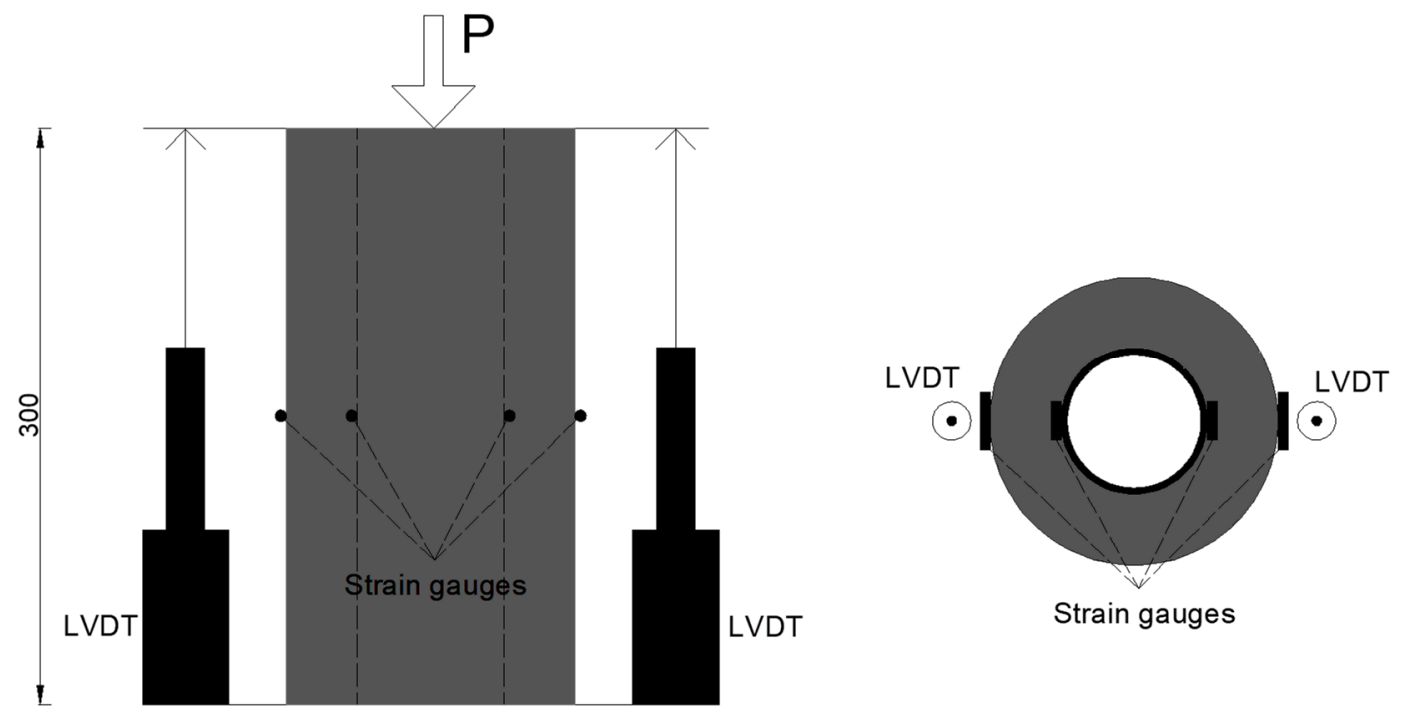

Figure 4. Locations of LVDTs and strain gauges.

\section{Experimental Results and Discussion}

\subsection{Failure Mode and Test Observation}

The results of the slump, air content and compressive strength tests measured using the Australian Standard methods for different mixes are shown in Table 1. Replacing $20 \%$ of the sand with fine rubber particles decreased $\mathbf{f}^{\prime}{ }_{\mathbf{c}}$ by $31.5 \%$, increased concrete slump by $47 \%$, and decreased concrete air content by $5.8 \%$. Replacing $20 \%$ of the concrete stone with coarse rubber particles decreased $\mathbf{f}^{\prime}{ }_{\mathbf{c}}$ by $45.8 \%$, increased concrete slump by $10 \%$, and decreased concrete air content by $24.7 \%$. The decrease of compressive strength due to rubber addition is due to the low rubber to concrete paste bond. The low hydrophilicity of rubber material decreases the interaction of rubber aggregate and concrete paste. This leads to separation of the rubber from the surrounding concrete binder at low levels of stresses. The higher strength reduction shown by the R20C mix compared with that of the R20F mix is attributed to the higher total volume of coarse rubber in addition to its relatively larger particle size, which caused an increase in the weak points in the concrete matrix that led to more strength reduction. The slump increase when partially replacing concrete aggregates by rubber is attributed to the increase in the level of free water in the concrete mix, as well as the increase in the weight ratio of cement to aggregate. The rubber aggregates had comparatively lower unit weight water absorption, and hydrophilicity, compared with the replaced aggregates, which caused the workability increase. Similar results have also been reported by $[35,36]$. The fine rubber showed a significant increase in concrete slump compared to a slight increase when using coarse rubber. This can be attributed to the relatively high fineness modulus of fine rubber compared with that of the replaced sand (2.2 times), but the difference between the fineness modulus of the coarse rubber and replaced stone was insignificant (only $5 \%$ difference). Increasing the fineness modulus of the concrete aggregates increases its workability [37]. The fresh concrete air content decrease using rubber might be attributed to the relatively high free water in the concrete matrix and hence, better compaction with ease of release of entrapped air. The high percentage of carbon black in the tyre rubber material can also help in decreasing the air content of Rubcrete, which was clearly observed when using higher weight/volume of rubber (coarse rubber) in the mixes.

Most of the hybrid DSTCs failed by rupture of the FRP tube at the middle third of the specimens' height. Figure 5 shows the failure modes of the specimens. No obvious local buckling was observed in the steel tube of specimens DS1 to DS8. However, local buckling was noted in specimens DS9 to DS12. At the specimen failure, the recorded local buckling locations in the steel tubes of specimens DS9, DS10, DS11, and DS12 were $75 \mathrm{~mm}, 87 \mathrm{~mm}, 138 \mathrm{~mm}$, and $102 \mathrm{~mm}$, respectively, on average, measured from the tops of the specimens. The local buckling may cause asymmetric distribution of the stress in 
the lateral directions, which resulted in FRP rupture in the specimens' top third. The results of the tested specimens are summarised in Table 3. In this table, $\mathbf{P}_{\mathbf{u}}$ is the column ultimate load, $\mathbf{A L}$ is the net loaded area of the column cross-section including the area of steel tube, $\mathbf{f}^{\prime}{ }_{\mathrm{cu}}$ is the column ultimate strength, and $\varepsilon_{\mathrm{cu}}$ is the corresponding ultimate axial strain, $\varepsilon_{\mathrm{hf}}$ is the corresponding ultimate hoop strain measured at the FRP tubes, $\varepsilon_{\mathrm{hs}}$ is the corresponding ultimate hoop strain measured at the steel tubes, and $T$ is the modulus of toughness. All axial and hoop strains were presented as average values recorded by the mounted LVDTs and strain gauges, respectively.

The ultimate rupture strain recorded for FRP tubes was about $71.5 \%$ of the rupture strain given by the manufacturer ( $\varepsilon_{\mathbf{h f}}$ in Table 3). Similar behaviour was observed by Lam and Teng [38] where the average ratio of hoop rupture strain to ultimate axial tensile strain of the FRP materials was about 0.63. This can be attributed to the stress concentrations in the FRP tube due to cracking and crushing of concrete, as well as local buckling of the steel tube, the overlapping areas of the FRP sheets, and/or the non-uniformity in concrete expansion [5]. At the ultimate strength of the tested columns, the average strain of the steel tubes, $\varepsilon_{\mathrm{hs}}$, was $47 \%$ of the average strain of the FRP tubes, $\varepsilon_{\mathrm{hf}}$. This could be attributed to the partial restraint of the steel tubes caused by the confined concrete compared to no restraint of the FRP tubes, considering the outward direction of the stresses while loading.

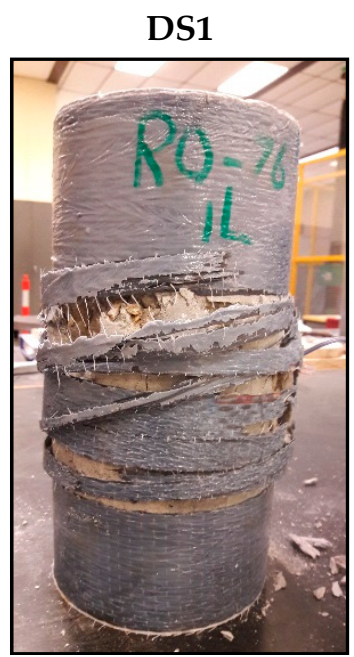

DS5

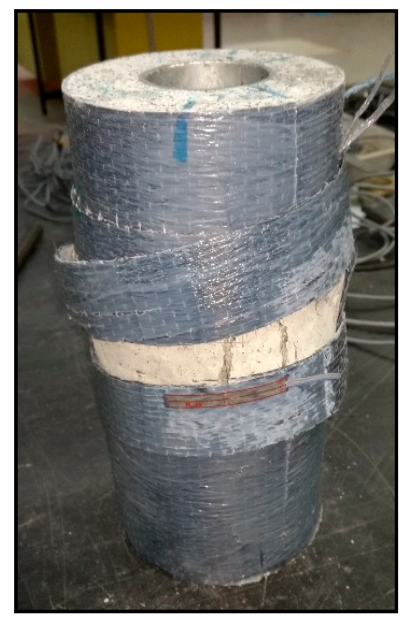

DS2

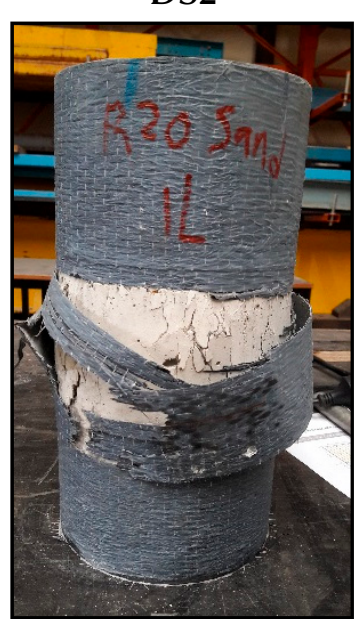

DS6

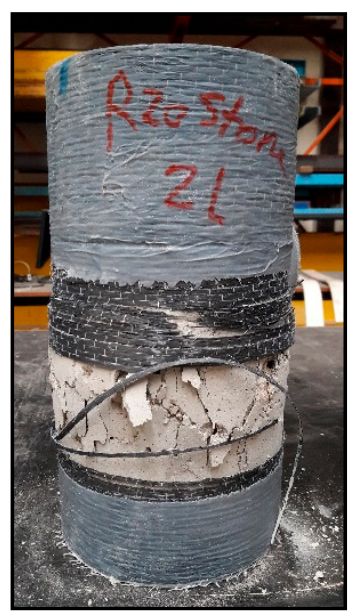

DS3

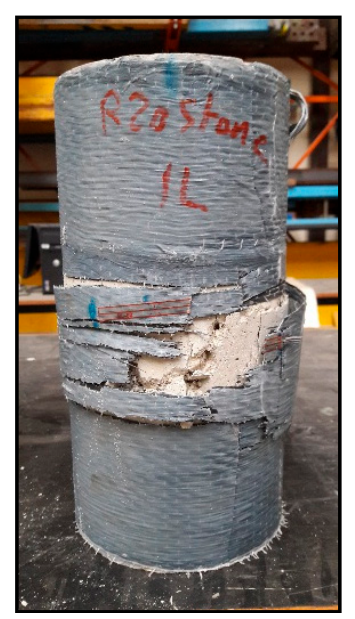

DS7

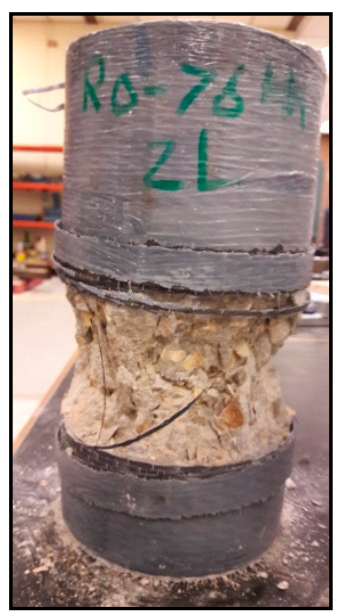

DS4

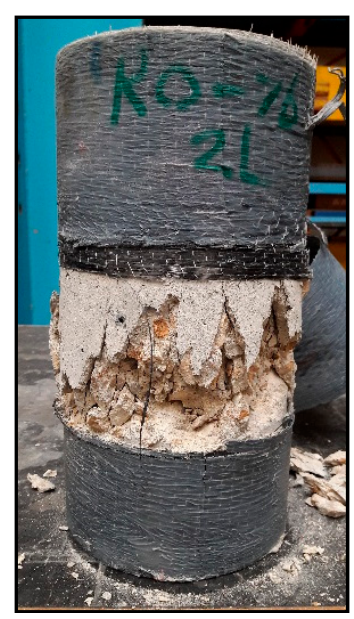

DS8

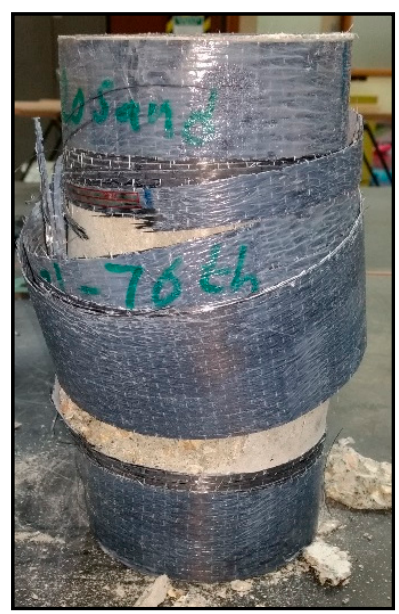

Figure 5. Cont. 

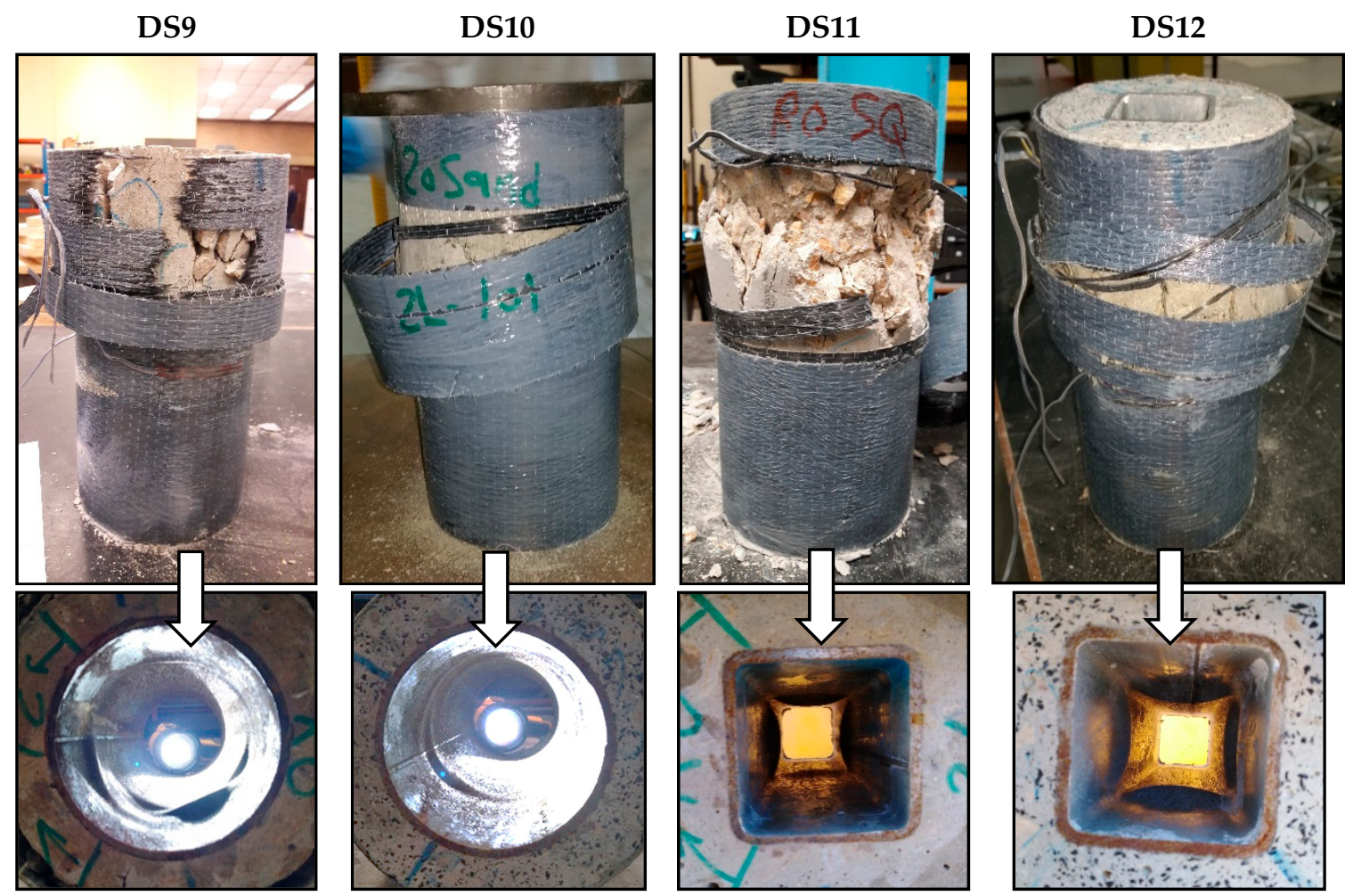

Figure 5. Failure mode of tested specimens.

Table 3. Stress-strain results.

\begin{tabular}{cccccccc}
\hline $\begin{array}{c}\text { Specimen } \\
\text { Code }\end{array}$ & $\begin{array}{c}\mathbf{P}_{\mathbf{u}} \\
\mathbf{( k N )}\end{array}$ & $\begin{array}{c}\mathbf{A L} \\
\left(\mathbf{m m}^{\mathbf{2}} \mathbf{)}\right.\end{array}$ & $\begin{array}{c}\mathbf{f}_{\mathbf{c u}} \\
\mathbf{( M P a )}\end{array}$ & $\begin{array}{c}\boldsymbol{\varepsilon}_{\mathbf{c u}} \\
\mathbf{( M i c r o} \text { Strain) }\end{array}$ & $\begin{array}{c}\varepsilon_{\mathbf{h f}} \\
\mathbf{( M i c r o ~ S t r a i n )}\end{array}$ & $\begin{array}{c}\varepsilon_{\text {hs }} \\
\text { (Micro Strain) }\end{array}$ & $\begin{array}{c}\mathbf{T} \\
\mathbf{( M P a} \text { Strain) }\end{array}$ \\
\hline DS1 & 1047 & 13,856 & 76 & 5837 & 6560 & 741 & 0.28 \\
DS2 & 848 & 13,856 & 61 & 7938 & 11,495 & 963 & 0.36 \\
DS3 & 782 & 13,856 & 56 & 7615 & 9672 & 4753 & 0.30 \\
DS4 & 1318 & 13,856 & 95 & 12,970 & 9910 & 4758 & 0.92 \\
DS5 & 1113 & 13,856 & 80 & 14,424 & 10,437 & 5714 & 0.83 \\
DS6 & 987 & 13,856 & 71 & 11,887 & 8266 & 5013 & 0.62 \\
DS7 & 1517 & 14,135 & 107 & 16,291 & 12,151 & 9362 & 1.33 \\
DS8 & 1326 & 14,135 & 94 & 17,959 & 11,729 & 6867 & 1.26 \\
DS9 & 1092 & 10,732 & 102 & 16,596 & 9435 & 7119 & 1.38 \\
DS10 & 904 & 10,732 & 84 & 14,399 & 10,260 & 6508 & 0.91 \\
DS11 & 1353 & 14,190 & 95 & 12,956 & 8935 & 2083 & 0.87 \\
DS12 & 1145 & 14,190 & 81 & 14,342 & 9231 & 3328 & 0.87 \\
\hline
\end{tabular}

\subsection{Axial Stress-Axial Strain Behaviour}

Figure 6 presents the applied compressive stress against the measured axial strains, as well as the hoop strains of both the outer and inner skin tubes. In this figure, positive strain values represent compressive strains, and negative values represent tensile strains. Generally, all specimens showed a bi-linear stress-strain relationship signified by two distinct stages. The first stage started at the loading commencement and continued until yielding or steel tube local buckling. At this stage, FRP Poisson's ratio is larger than that in concrete, which allows the FRP tube to expand easily in the lateral direction with the specimen loading. The second stage started when yielding or local buckling of the steel tube occurred and continued until the specimen failure. During this stage, concrete cracks developed, which resulted in a higher dilation, and hence expansion, of concrete. This activated the FRP-confining layer, which led to a linear increase of stress and strain until FRP rupture. Similar to the axial stress-strain relationship, two stages of response were observed for the hoop stress-strain relationship, as shown in Figure 6 (left side of each figure). 


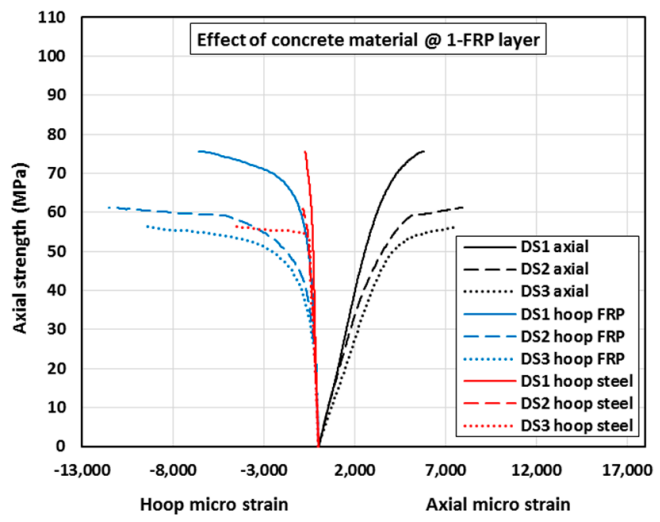

(a)

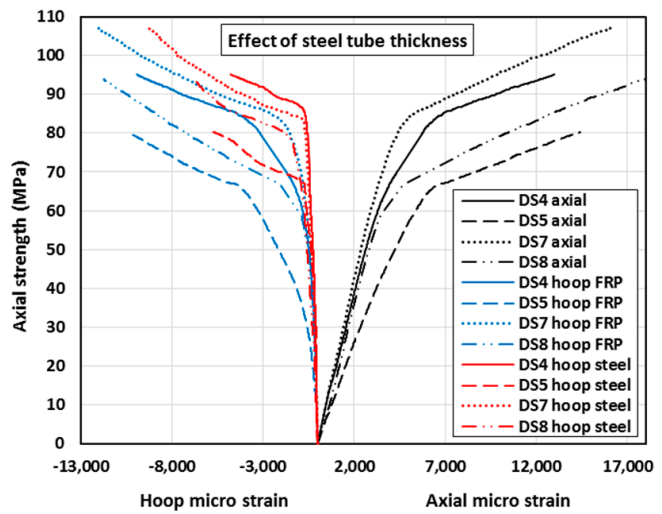

(c)

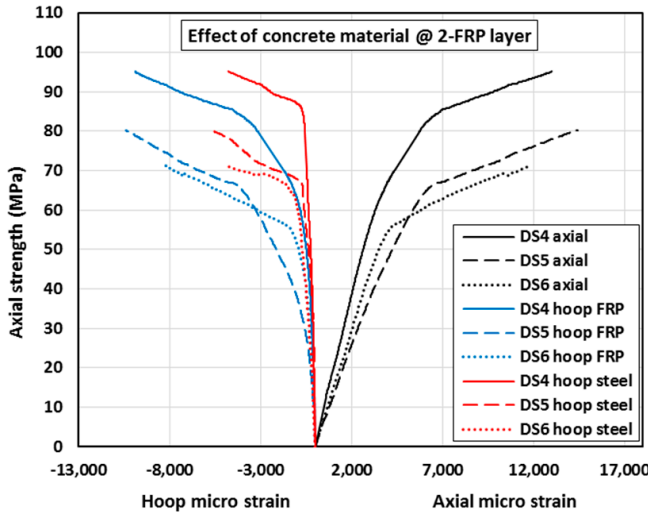

(b)

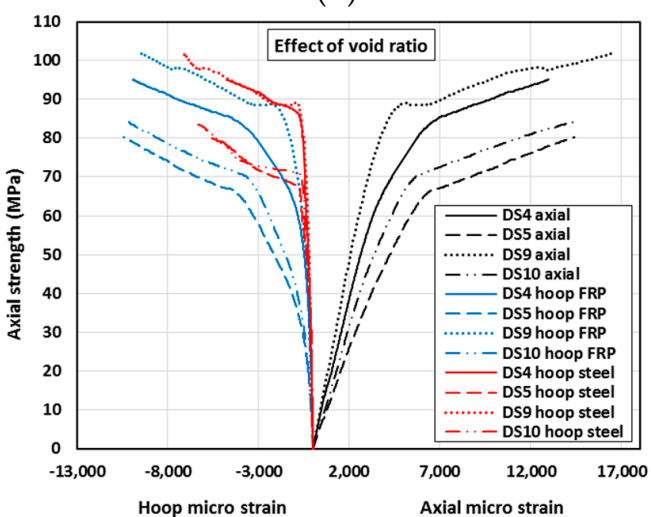

(d)

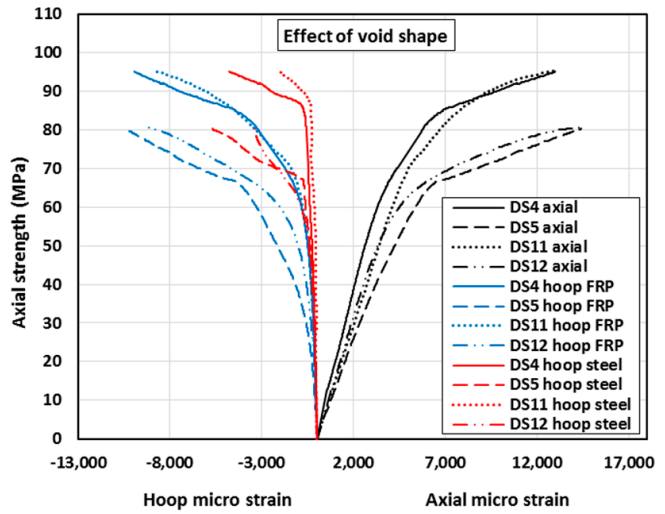

(e)

Figure 6. Axial and hoop stress-strain relationships: (a) Effect of concrete material at 1-FRP layer, (b) effect of concrete material at 2-FRP layer, (c) effect of steel tube thickness, (d) effect of void ratio, and (e) effect of void shape.

The effect of concrete material (Rubcrete versus conventional concrete) on the hybrid DSTCs can be observed by comparing the results of specimens DS1 to DS3 at 1-layer FRP tube thickness (Figure 6a), and by comparing the results of specimens DS4 to DS6 at 2-layer FRP tube thickness (Figure 6b). Replacing 20\% of concrete sand with fine rubber at 1-layer FRP tube thickness decreased the column's $\mathbf{f}^{\prime}$ cu by $19 \%$ and increased the $\varepsilon_{\mathbf{c u}}, \varepsilon_{\mathbf{h f}}$, and $\varepsilon_{\mathbf{h s}}$ by $1.4,1.8$, and 1.3 times, respectively, and at 2-layer, it decreased the column's $\mathbf{f}_{\text {cu }}^{\prime}$ by $16 \%$ and increased the $\varepsilon_{\mathrm{cu}}, \varepsilon_{\mathrm{hf}}$, and $\varepsilon_{\mathrm{hs}}$ by $11 \%, 5 \%$, and $20 \%$, respectively. Replacing $20 \%$ of concrete stone by coarse rubber at 1-layer FRP, decreased the column's $\mathbf{f}^{\prime}$ cu by $25 \%$ and increased the $\varepsilon_{\mathrm{cu}}, \varepsilon_{\mathrm{hf}}$, and $\varepsilon_{\mathrm{hs}}$ by $1.3,1.5$, and 6.4 times, respectively, and at 2-layer it decreased the column's $\mathbf{f}^{\prime}{ }_{\mathrm{cu}}, \varepsilon_{\mathrm{cu}}$, and $\varepsilon_{\mathrm{hf}}$ by $25 \%, 8 \%$, and $17 \%$, respectively, but slightly increased the $\varepsilon_{\text {hs }}$ by $5 \%$. 
On average, while the unconfined strength of concrete at the material level reduced by $31.5 \%$ and $45.8 \%$ for R20F and R20C, respectively, compared to the control mix, R0, the strength of the DSTC specimens made up of R20F and R20C concrete materials reduced by only $16-19 \%$ and $25 \%$. Hence, using Rubcrete with fine rubber particles, in hybrid DSTCs, is able to enhance the column axial and hoop strains with much less adverse effect on the column ultimate capacity, compared with using Rubcrete in an unconfined/non-reinforced state.

Figure $6 \mathrm{a}, \mathrm{b}$ show the effect of the FRP tube thickness of the hybrid DSTCs by comparing the results of specimens DS1 to DS3 (with one layer of FRP) to those of DS4 to DS6 (with two layers of FRP). Doubling the FRP tube thickness increased the $\mathbf{f}^{\prime}{ }_{\mathrm{cu}}, \varepsilon_{\mathrm{cu}}, \varepsilon_{\mathrm{hf}}$, and $\varepsilon_{\mathrm{hs}}$ by $1.25,2.22,1.51$, and 6.42 times, respectively, for the R0 concrete mix. The $\mathbf{f}^{\prime}{ }_{\mathrm{cu}}, \boldsymbol{\varepsilon}_{\mathrm{cu}}$, and $\varepsilon_{\mathrm{hs}}$ increased by $1.31,1.82$, and 5.93 times, respectively for the R20F concrete mix, and by $1.26,1.56$, and 1.05 times, respectively for the R20C concrete mix. Increasing the FRP tube thickness decreased $\varepsilon_{\mathrm{hf}}$ by $9 \%$ and $15 \%$ when using R20F and R20C concrete mixes, respectively. Even though Rubcrete has lower strength than that of the traditional concrete, the ultimate strength enhancement in the specimens that utilized rubber was greater than that of the control traditional concrete specimens. This was attributed to rubber Poisson's ratio and Young's modulus that resulted in concrete with lower crushing under the FRP tube compared to the traditional concrete. This helps to disperse the stresses and hence decrease the concentration of the stress in the confining tube and hence delays the rupturing of the FRP tube.

The effect of steel tube thickness was shown in Figure $6 \mathrm{c}$ by comparing the results of specimens DS4, DS5, DS7, and DS8. Increasing the steel tube thickness by $40 \%$ (from $3.2 \mathrm{~mm}$ to $4.5 \mathrm{~mm}$ ) increased the $\mathbf{f}^{\prime}{ }_{\mathrm{cu}}, \varepsilon_{\mathrm{cu}}, \varepsilon_{\mathrm{hf}}$, and $\varepsilon_{\mathrm{hs}}$ by $13 \%, 26 \%, 23 \%$, and $97 \%$, respectively when using the R0 mix, and by $17 \%, 25 \%, 12 \%$, and $20 \%$, respectively when using the R20F mix. The enhancements in the column ultimate characteristics are related to the increase in the net loaded cross-section area (AL in Table 3), which consequently increased the column axial capacity and delayed the yielding and buckling of the steel tube and hence, provided a better performance. At a steel tube thickness of $3.2 \mathrm{~mm}$, using Rubcrete in specimen DS5 decreased $\mathbf{f}_{\text {cu }}^{\prime}$ by $16 \%$, but increased $\varepsilon_{\mathbf{c u}}, \varepsilon_{\mathbf{h f}}$, and $\varepsilon_{\mathbf{h s}}$ by $11 \%, 5 \%$, and $20 \%$, respectively compared with those of specimen DS4. At a steel tube thickness of $4.5 \mathrm{~mm}$, using Rubcrete in specimen DS8 decreased $\mathbf{f}^{\prime}{ }_{\mathrm{cu}}, \varepsilon_{\mathrm{hf}}$, and $\varepsilon_{\mathrm{hs}}$ by $12 \%, 3 \%$, and $27 \%$, respectively, but increased $\varepsilon_{\mathrm{cu}}$ by $10 \%$, compared with those of specimen DS7.

Specimens DS9 and DS10 were made with a diameter void ratio of $66 \%$ using a circular steel tube of $99.0 \mathrm{~mm}$ diameter that had the same cross sectional area as the $76.1 \mathrm{~mm}$ diameter steel tube used to form a diameter void ratio of $51 \%$ in specimens DS4 and DS5. As shown in Figure $6 \mathrm{~d}$, when conventional concrete R0 was used, increasing the DSTC diameter void ratio by about 30\% (from $51 \%$ in specimen DS4 to $66 \%$ in specimen DS9), increased the $\mathbf{f}_{\mathrm{cu}}^{\prime}, \boldsymbol{\varepsilon}_{\mathrm{cu}}$, and $\varepsilon_{\mathrm{hs}}$ by $7 \%, 28 \%$, and $50 \%$, respectively, but decreased $\varepsilon_{\text {hf }}$ by $5 \%$. However, when R20F was used (comparing specimen DS5 to specimen DS10), the $\mathbf{f}_{\text {cu }}^{\prime}$ and $\varepsilon_{\mathrm{hs}}$ increased by $5 \%$ and $14 \%$, respectively with no effect on $\varepsilon_{\mathrm{cu}}$, and $\varepsilon_{\mathrm{hf}}$ decreased slightly by only $2 \%$. Due to the void ratio increase with constant outer diameter, the sandwiched concrete cross sectional area decreased, which caused reduction in the ultimate load of the tested columns, as shown in Table 3. However, the rate of concrete cross sectional area decrease was higher than the rate of ultimate load decrease, which resulted in higher axial strength for DSTCs with a higher void ratio. This provides additional architectural benefits to this column structural system, as more internal duct space can help in accommodating more non-structural building services and utilities, as well as enabling easier maintenance of the inner steel tube and hence higher structure sustainability. At a diameter void ratio of $66 \%$, using Rubcrete in specimen DS10 decreased $\mathbf{f}^{\prime}{ }_{\mathrm{cu}}, \varepsilon_{\mathrm{cu}}$, and $\varepsilon_{\mathrm{hs}}$ by $18 \%, 13 \%, 8 \%$, respectively, but increased $\varepsilon_{\mathrm{hf}}$ by $9 \%$ compared with those of specimen DS9.

The effect of using a square void shape compared with a circular void shape can be observed in Figure 6e by comparing the results of specimens DS4, DS5, DS11, and DS12. The axial capacity of the steel tube was kept constant for this comparison. Using a square void shape in DSTCs showed no effect on both the $\mathbf{f}^{\prime}{ }_{\mathrm{cu}}$ and $\varepsilon_{\mathrm{cu}}$. This adds more flexibility to choose the central void shape of this structural system to suit the construction requirements. On the other hand, the square void ratio decreased the 
measured hoop strains in both the FRP and steel tubes compared with those of the circular void shape. The square shape decreased the $\varepsilon_{\mathrm{hf}}$ and $\varepsilon_{\mathrm{hs}}$ by $10 \%$ and $56 \%$, respectively, when using the R0 mix; and by $12 \%$ and $42 \%$, respectively, when using the R20F mix. This can be attributed to the non-uniform distribution of strain along the circumference of the square steel tube compared to uniform distribution in the circular steel tube. The corners in the square cross-sectional tube are stiffer than the side walls, which act as supports for the tube in the lateral direction. This decreases the lateral expansion of the steel tube under load and consequently decreases the external FRP tube hoop strains. In addition, this supporting action helps in forming clear local buckling in the steel tube walls compared with no obvious local buckling in the corresponding specimens with circular steel tubes, as shown in Figure 5 (specimens DS11 and DS12). Using Rubcrete with square void shape in specimen DS12 decreased $\mathbf{f}^{\prime}{ }_{\mathbf{c u}}$ by $15 \%$, but increased $\varepsilon_{\mathrm{cu}}, \varepsilon_{\mathrm{hf}}$, and $\varepsilon_{\mathrm{hs}}$ by $11 \%, 3 \%$, and $60 \%$, respectively, compared with those of specimen DS11.

\subsection{Modulus of Toughness}

The modulus of toughness $(T)$ of each specimen is shown in Table 3 and plotted in Figure 7. At 1-layer FRP tube thickness, using R20F Rubcrete increased $T$ by $29 \%$ compared with R0 conventional concrete; however, using R20C Rubcrete did not show any significant effect on $T$. At 2-layer FRP tube thickness, using R20F and R20C Rubcrete decreased $T$ by $10 \%$ and 33\%, respectively, compared with the $\boldsymbol{T}$ of R0 conventional concrete. Different $\boldsymbol{T}$ performance of Rubcrete was also observed at 2-layer FRP tube thickness with a thicker steel tube, higher void ratio, or square void shape, where Rubcrete showed a $T$ less than or equal to that of conventional concrete. This variability might be attributed to the tendency of the steel tube to locally buckle, which cannot be seen by the naked eye, under the relatively high axial load maintained by using 2-layer FRP thickness. This can result in stress concentration on the sandwiched Rubcrete and hence, less strain capacity and relatively earlier rupture of the specimens. The $T$ increased by $2-3$ times when increasing the FRP tube thickness due to the increased axial capacity and ultimate strain. For the same reasons, increasing the steel tube thickness increased the $\boldsymbol{T}$ by $45 \%$ and $52 \%$ when using R0 and R20F mixes, respectively. The void ratio increase enhanced the $\boldsymbol{T}$ of the DSTCs by $50 \%$ and $9 \%$ when using R0 and R20F mixes, respectively. This was attributed to the relatively higher stiffness of the steel tube used to increase the void ratio, which resulted in higher strength values at given strains and hence, greater area under the stress-strain curve. The void shape did not significantly affect the $\boldsymbol{T}$ values of the DSTCs as only $\pm 5 \%$ change in $\boldsymbol{T}$ occurred, regardless of the concrete mix used. This was due to the high similarity of the axial stress-strain curves of specimens with different void shapes shown in Figure 6e. From the above results, using Rubcrete with fine rubber particles has a degree of variability in its effect on DSTC toughness where it can show higher, less, or equal $T$ to that of conventional concrete. Comparison between Rubcrete and conventional concrete at the same strength is recommended for future research.

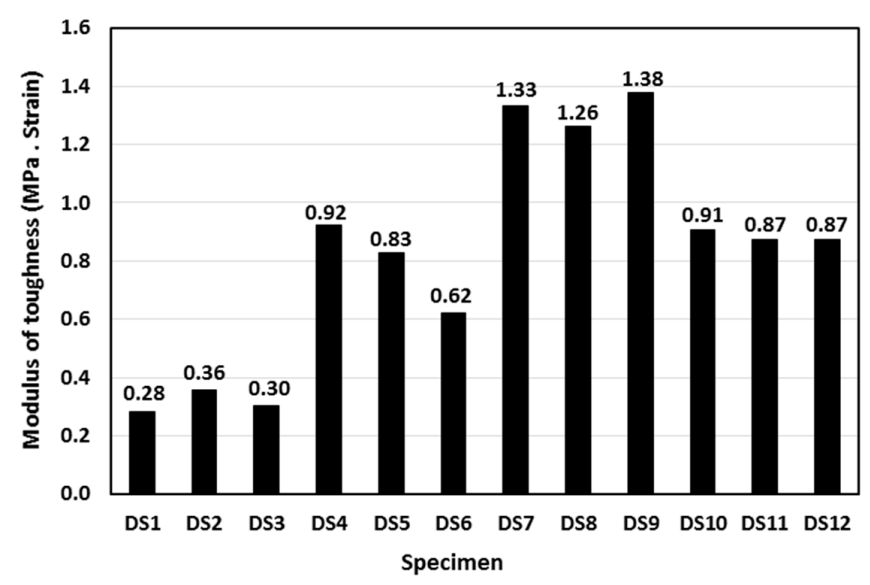

Figure 7. Modulus of toughness. 


\subsection{Axial Strain-Hoop Strain Behaviour}

The axial strain-hoop strain behaviour is a representation of the dilation behaviour of the hybrid DSTC s tested in this study. Figure 8 shows the recorded axial strains versus the corresponding hoop strains measured at the mid-heights of both the steel tube and the FRP tube. Generally, the axial strain-hoop strain curves are bi-linear with a transition zone. The behaviour of this transition zone is dependent on the skin tube material. For the FRP tube, the transition zone occurred at 3000-5000 axial micro strain, while for the steel tube, it occurred at 7000-10,000 axial micro strain. As the steel tubes used were thicker than the FRP tubes used, the steel tubes were relatively stiffer, which maintained a lower dilation rate than that of the FRP tubes and hence, delayed transition zone occurrence. The two lines of the bi-linear axial stain-hoop strain curve, represent the initial and final dilations of the specimens, while, all the tested specimens showed approximately similar initial dilation behaviour regardless of the specimen variables they exhibited at different final dilations. As shown in Figure 8a, nearly no difference in the dilation behaviour was detected when using Rubcrete or conventional concrete. However, using thicker FRP tubes significantly decreased the final dilation of the DSTCs. By increasing the thickness of FRP layer, the tube stiffness increased, which resulted in lower hoop strains under a given load. The effect of steel tube thickness is shown in Figure 8b, where no significant effect occurred on the dilation behaviour when using conventional concrete; however, smoother dilation was recorded when using Rubcrete. The void ratio increase had no effect on the FRP tube dilation rate when Rubcrete was used, but the dilation rate decreased when conventional concrete was used. This was attributed to the relatively high level of local buckling that took place at $75 \mathrm{~mm}$ height measured from the specimen top, which concentrated the stresses at that level but not the specimen mid-height. This stress concentration also caused higher steel tube hoop strains compared with those of smaller void ratios, as shown in Figure 8c. Due to the clear local buckling that occurred in the steel tubes of DSTCs with square void shapes, lower dilation rates in both the steel and FRP tubes were recorded compared with those of the circular shape, regardless of the concrete material used, as shown in Figure 8d.

The Rubcrete specimens, especially with R20F concrete, presented axial and hoop strains higher than those displayed by the traditional concrete specimens. This was due to the higher deformability of Rubcrete compared to that of the counterpart concrete. This indicates the higher effectiveness of Rubcrete compared with conventional concrete in DSTC systems.

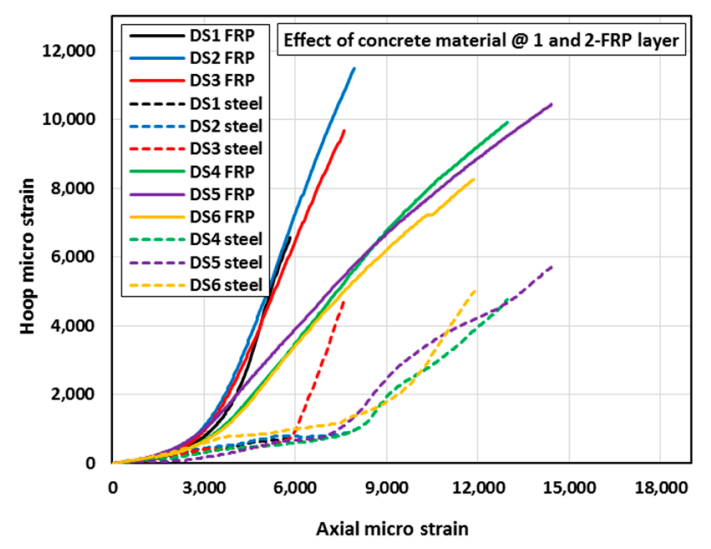

(a)

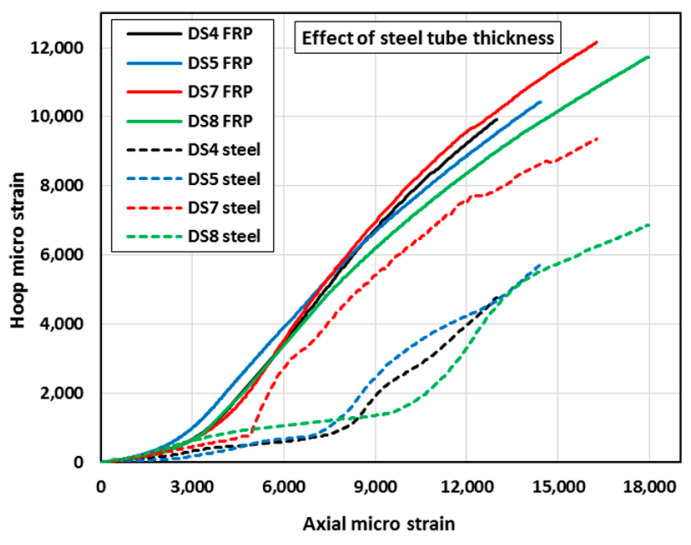

(b)

Figure 8. Cont. 


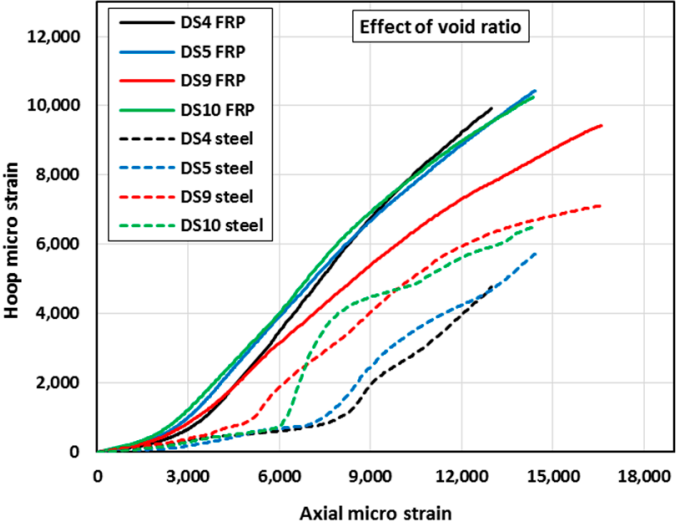

(c)

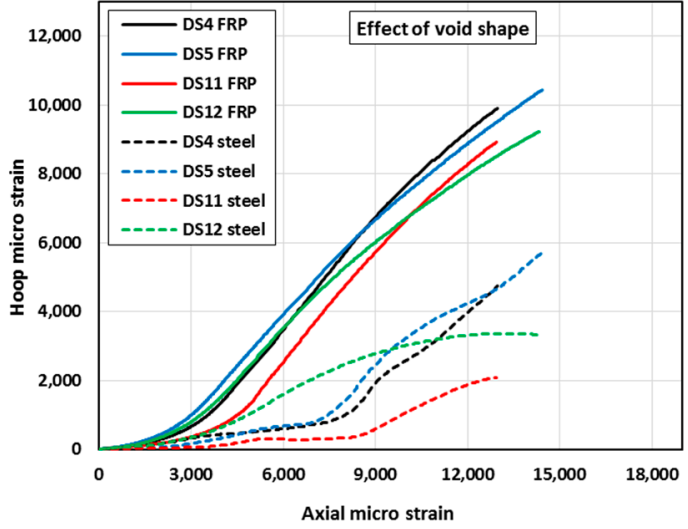

(d)

Figure 8. Axial strain vs. hoop strain: (a) Effect of concrete material at 1 and 2-FRP layer, (b) effect of steel tube thickness, (c) effect of void ratio, and (d) effect of void shape.

\subsection{Concrete Volumetric Strain Behaviour}

The concrete volumetric strain $\left(\varepsilon_{v}\right)$ is defined here as the ratio of concrete volume change $(\Delta V)$ under given stress to the original concrete volume $(V)$. Using this concept and assuming full contact between the concrete and both inner and outer skin tubes, the concrete volumetric strain, $\varepsilon_{v}$, for the DSTCs can be calculated as:

$$
\varepsilon_{v}=\frac{\Delta V}{V}=\frac{(A+\Delta A)(L+\Delta L)-A \cdot L}{A \cdot L}=\frac{A \cdot \Delta L+L \cdot \Delta A}{A \cdot L}=\frac{\Delta L}{L}+\frac{\Delta A}{A}
$$

where; $L$ is the length of the concrete specimen, $\Delta L$ is the change in concrete length under stress, the ratio of $\Delta L / L$ is the concrete axial strain $\left(\varepsilon_{c}\right), A$ is the concrete cross-sectional area, and $\Delta A$ is the change in concrete cross-sectional area under stress,

$$
\begin{gathered}
A=\frac{\pi}{4}\left[D_{o}^{2}-D_{i}^{2}\right] \\
\Delta A=\frac{\pi}{4}\left[\left(D_{o}+\Delta D_{o}\right)^{2}-\left(D_{i}+\Delta D_{i}\right)^{2}\right]-\frac{\pi}{4}\left[D_{o}^{2}-D_{i}^{2}\right]
\end{gathered}
$$

where; $\boldsymbol{D}_{\boldsymbol{o}}$ is the outer diameter of sandwiched concrete, $\Delta \boldsymbol{D}_{\boldsymbol{o}}$ is the change in concrete outer diameter under stress, $\boldsymbol{D}_{\boldsymbol{i}}$ is the inner diameter of sandwiched concrete, and $\Delta \boldsymbol{D}_{\boldsymbol{i}}$ is the change in concrete inner diameter under stress. Substituting the value of $A$ and $\Delta A$ gives,

$$
\begin{gathered}
\frac{\Delta A}{A}=\frac{2 D_{o} \cdot \Delta D_{o}}{D_{o}^{2}-D_{i}^{2}}-\frac{2 D_{i} \cdot \Delta D_{i}}{D_{o}^{2}-D_{i}^{2}}=2 \frac{\Delta D_{o}}{D_{o}}\left(\frac{D_{o}}{D_{o}-\frac{D_{i}^{2}}{D_{o}}}\right)-2 \frac{\Delta D_{i}}{D_{i}}\left(\frac{D_{i}}{\frac{D_{o}^{2}}{D_{i}}-D_{i}}\right) \\
\varepsilon_{v}=\varepsilon_{c}+2 \varepsilon_{h o}\left(\frac{1}{1-\left(\frac{D_{i}}{D_{o}}\right)^{2}}\right)-2 \varepsilon_{h i}\left(\frac{1}{\left(\frac{D_{o}}{D_{i}}\right)^{2}-1}\right)
\end{gathered}
$$

where; $\varepsilon_{h o}$ and $\varepsilon_{h i}$ are the hoop strains at the outer and inner skin tubes, respectively.

To calculate the volumetric strain using Equation (5), $\varepsilon_{h o}$ was taken as the strain at the FRP tube, and $\varepsilon_{h i}$ was taken as the strain at the steel tube. Negative values for compressive axial strain and positive values for tensile hoop strain were considered. A negative and positive value of $\varepsilon_{v}$ shows that the column specimen is in contraction and expansion, respectively. The volumetric strain determined using Equation (5) was drawn versus the axial compressive strength in Figure 9 for some specimens. Until the concrete reached its unconfined compressive strength under loading, it was in contraction with negligible difference between Rubcrete and conventional concrete. After that, specimens experienced 
a higher level of stress, leading to formation of cracks and subsequently a significant increase in the expansion rate and hence, increased volumes before failure occurred. As shown in Figure 9a, at different FRP thickness, R20F and R20C concrete mixes exhibited higher dilation (expansion) rates than that of R0. Increasing the FRP tube thickness decreased the concrete expansion rate. This was due to the specimen stiffness increase in the case of thicker FRP encasement, which decreased the measured hoop strains. Increasing the thickness of the steel tube and the void ratio decreased the concrete dilation rate when using conventional concrete, see Figure $9 \mathrm{~b}$. The same behaviour was observed for Rubcrete; however, increasing the void ratio showed an insignificant effect on Rubcrete dilation. This confirms the effectiveness of using Rubcrete material in DSTC systems with flexibility in having more internal duct space and hence easier maintenance of the column.

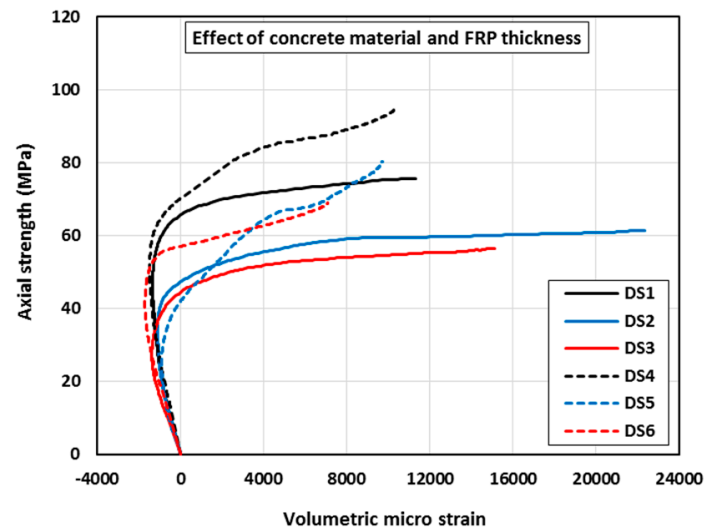

(a)

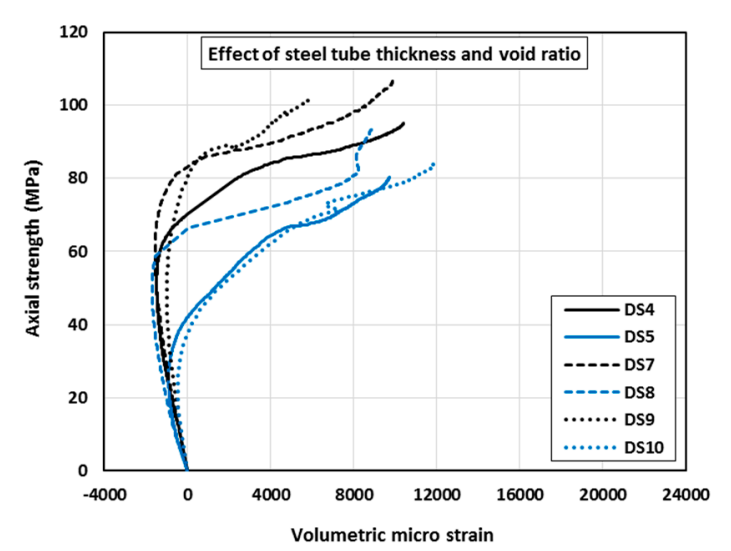

(b)

Figure 9. Volumetric strain behaviour versus applied axial stress of some tested specimens: (a) Effect of concrete material and FRP thickness, and (b) effect of steel tube thickness and void ratio.

\section{Conclusions}

In this investigation, circular hybrid DSTCs made out of Rubcrete sandwiched between FRP as the outer skin and steel as the inner skin were tested under axial compression loading. Rubcrete with $0 \%$ and $20 \%$ rubber content was used as concrete mixes in the tested columns. FRP tubes with different number of layers were used as external confinement of the columns. The effects of inner steel wall thicknesses, void ratios, and void shapes were also examined and compared for Rubcrete and conventional DSTCs. The main findings of this investigation are summarised below.

1. Using Rubcrete with fine rubber particles in hybrid DSTCs resulted in enhancement in the column's axial and hoop strains when used with steel tube thickness of $3.2 \mathrm{~mm}$ and diameter void ratio of $51 \%$. However, an adverse effect occurred on the column ultimate capacity, but with a much lower rate of decrease, compared with using Rubcrete in an unconfined/non-reinforced state. Compared with conventional concrete, when Rubcrete was used in an unconfined state, the strength reduced by $31.5 \%$; however, the strength reduction was only about $16-19 \%$ when the concrete was confined. Hence, confinement can partially mitigate the negative effect of rubber on the strength properties of concrete.

2. Using Rubcrete with a thicker steel tube of $4.5 \mathrm{~mm}$ and higher void ratio of $66 \%$ showed adverse effects on most of the DSTC characteristics. However, Rubcrete showed enhanced axial and hoop strains when used with square void shape compared with those of circular void shape.

3. Doubling the FRP tube thickness increased the ultimate strength of DSTC by 1.25 times for R0, 1.31 for R20F, and 1.26 for R20C. Increasing the steel tube thickness by $40 \%$ increased the ultimate strength by $13 \%$ when using R0, and by $17 \%$ when using R $20 \mathrm{~F}$.

4. Regardless of the concrete type, using a higher diameter void ratio resulted in strength enhancement, which provides additional architectural benefits to this column structural system, 
as more internal duct space can help in accommodating more non-structural building services and utilities, as well as reducing the total self-weight of the column.

5. Smoother dilation behaviour was recorded when using Rubcrete compared with conventional concrete. The void ratio increase had no effect on the FRP tube dilation rate when Rubcrete was used, but the dilation rate decreased when conventional concrete was used. Lower dilation rates in both the steel and FRP tubes were recorded when a square void shape was used compared with those of the circular shape, regardless of the concrete material used.

6. Rubcrete mixes exhibited a higher volumetric strain rate than that of conventional concrete. By increasing the steel tube thickness, the concrete volumetric strain rate decreased when using Rubcrete; however, increasing the void ratio showed an insignificant effect on the Rubcrete volumetric strain rate.

7. Overall, Rubcrete performed well when replacing conventional concrete in DSTC under axial compression. More experimental work is recommended in future studies to investigate the behaviour of Rubcrete DSTC under creep, extreme, and harsh loadings.

Author Contributions: Conceptualization, O.Y.; Data curation, O.Y.; Formal analysis, O.Y. and R.H.; Funding acquisition, J.E.M.; Investigation, O.Y. and R.H.; Methodology, O.Y. and R.H.; Project administration, J.E.M., and Y.Z.; Resources, J.E.M.; Software, O.Y.; Supervision, O.Y. and R.H.; Writing-original draft, O.Y.; Writing-review \& editing, R.H., J.E.M., and Y.Z.

Funding: This research received no external funding.

Acknowledgments: The authors would like to thank the following providers who donated materials to this experimental project: ResourceCo Pty. Ltd., Adelaide Brighton Cement Pty. Ltd., and Tyrecycle Pty. Ltd. The authors also would like to acknowledge the support of Tom Benn, Henry Senko, Tim Golding, and staff who helped in this work: Matthew Coorey, Blake Saunders, Dino Anzellotti, and Gia Vo.

Conflicts of Interest: The authors declare no conflict of interest.

\section{References}

1. Segre, N.; Joekes, I. Use of tire rubber particles as addition to cement paste. Cem. Concr. Res. 2000, 30, 1421-1425. [CrossRef]

2. Pacheco-Torgal, F.; Ding, Y.; Jalali, S. Properties and durability of concrete containing polymeric wastes (tyre rubber and polyethylene terephthalate bottles): An overview. Constr. Build. Mater. 2012, 30, 714-724. [CrossRef]

3. Brindley, F. COAG Standing Council on Environment and Water Study into Domestic and International Fate of End-Of-Life Tyres: Final Report/Fraser Brindley, Emma Mountjoy, Gavin Mountjoy; Hyder Consulting: Melbourne, Australia, 2012.

4. Downard, J.; Singh, A.; Bullard, R.; Jayarathne, T.; Rathnayake, C.M.; Simmons, D.L.; Wels, B.R.; Spak, S.N.; Peters, T.; Beardsley, D.; et al. Uncontrolled combustion of shredded tires in a landfill—Part 1: Characterization of gaseous and particulate emissions. Atmos. Environ. 2015, 104, 195-204. [CrossRef] [PubMed]

5. Youssf, O.; ElGawady, M.A.; Mills, J.E.; Ma, X. An experimental investigation of crumb rubber concrete confined by fibre reinforced polymer tubes. Constr. Build. Mater. 2014, 53, 522-532. [CrossRef]

6. Gupta, T.; Chaudhary, S.; Sharma, R.K. Assessment of mechanical and durability properties of concrete containing waste rubber tire as fine aggregate. Constr. Build. Mater. 2014, 73, 562-574. [CrossRef]

7. Youssf, O.; ElGawady, M.A.; Mills, J.E.; Ma, X. Analytical Modeling of the Main characteristics of Crumb Rubber Concrete. ACI-Spec. Publ. 2017, 314, 1-18.

8. Atahan, A.O.; Yücel, A.Ö. Crumb rubber in concrete: Static and dynamic evaluation. Constr. Build. Mater. 2012, 36, 617-622. [CrossRef]

9. Youssf, O.; ElGawady, M.A.; Mills, J.E. Experimental Investigation of Crumb Rubber Concrete Columns Under Seismic Loading. Structures 2015, 3, 13-27. [CrossRef]

10. Hassanli, R.; Youssf, O.; Mills, J.E. Experimental investigations of reinforced rubberized concrete structural members. J. Build. Eng. 2017, 10, 149-165. [CrossRef]

11. Youssf, O.; ElGawady, M.A.; Mills, J.E. Static cyclic behaviour of FRP-confined crumb rubber concrete columns. Eng. Struct. 2016, 113, 371-387. [CrossRef] 
12. Youssf, O.; Hassanli, R.; Mills, J.E. Mechanical performance of FRP-confined and unconfined crumb rubber concrete containing high rubber content. J. Build. Eng. 2017, 11, 115-126. [CrossRef]

13. Hassanli, R.; Youssf, O.; Julie, E.M. Seismic Performance of Precast Posttensioned Segmental FRP-Confined and Unconfined Crumb Rubber Concrete Columns. J. Compos. Constr. 2017, 21, 04017006. [CrossRef]

14. Gholampour, A.; Ozbakkaloglu, T.; Hassanli, R. Behavior of rubberized concrete under active confinement. Constr. Build. Mater. 2017, 138, 372-382. [CrossRef]

15. Abdelkarim, O.I.; ElGawady, M.A. Behavior of hollow FRP-concrete-steel columns under static cyclic axial compressive loading. Eng. Struct. 2016, 123, 77-88. [CrossRef]

16. Yu, T.; Zhang, B.; Cao, Y.; Teng, J.-G. Behavior of hybrid FRP-concrete-steel double-skin tubular columns subjected to cyclic axial compression. Thin-Walled Struct. 2012, 61, 196-203. [CrossRef]

17. Yu, T.; Teng, J. Behavior of hybrid FRP-concrete-steel double-skin tubular columns with a square outer tube and a circular inner tube subjected to axial compression. J. Compos. Constr. 2012, 17, 271-279. [CrossRef]

18. Shanmugasundari, M.; Sakthieswaran, N.; Brintha, S.G.; Babu, G.O. A Comparative Study of Ultimate Strength on Hollow Rectangular Filled Concrete Tube-IN-Tube Section-A Review. Int. J. Res. Appl. Sci. Eng. Technol. 2016, 4, 779-782.

19. Cavill, G.; Yu, T. Rectangular hybrid FRP-concrete-steel double-skin tubular columns: Stub column tests. In Proceedings of the 23rd Australasian Conference on the Mechanics of Structures and Materials (ACMSM23), Bryon Bay, Australia, 9-12 December 2014.

20. Yu, T.; Wong, Y.L.; Teng, J.G. Behavior of Hybrid FRP-Concrete-Steel Double-Skin Tubular Columns Subjected to Eccentric Compression. Adv. Struct. Eng. 2010, 13, 961-974. [CrossRef]

21. Ozbakkaloglu, T. Reflections on Mechanisms Affecting the Behavior of FRP-Concrete-Steel Double-Skin Tubular Columns. Key Eng. Mater. 2016, 705, 323. [CrossRef]

22. Yao, J.; Jiang, T.; Xu, P.; Lu, Z. Experimental investigation on large-scale slender FRP-concrete-steel double-skin tubular columns subjected to eccentric compression. Adv. Struct. Eng. 2015, 18, 1737-1746. [CrossRef]

23. Dong, C.; Ho, J. Concrete-filled Double-skin Tubular Columns with External Steel Rings. In Proceedings of the Australian Earthquake Engineering Society 2012 Conference, Gold Coast, Australia, 7-9 December 2012.

24. Wen, L.; Tong, W.; Yu, N. Research on the Influence of Size Effect for the mechanical Performance of GFRP tube concrete steel tube composite column under axial compression. Iop Conf. Ser. Earth Environ. Sci. 2017, 81, 012125.

25. Teng, J.-G.; Yu, T.; Wong, Y.; Dong, S. Hybrid FRP-concrete-steel tubular columns: Concept and behavior. Constr. Build. Mater. 2007, 21, 846-854. [CrossRef]

26. Wang, J.; Liu, W.; Zhou, D.; Zhu, L.; Fang, H. Mechanical behaviour of concrete filled double skin steel tubular stub columns confined by FRP under axial compression. Steel Compos. Struct 2014, 17, 431-452. [CrossRef]

27. Mathew, D.; Parvati, T.S.; Joanna, P.S.; Sakaria, E. Cyclic Behaviour of Concrete Filled Double Skinned Tubular Columns (Inner and Outer Square Light Gage Tube). Int. J. Eng. Res. Technol. 2014, 3, 802-804.

28. Zhang, B.; Teng, J.G.; Yu, T. Experimental behavior of hybrid FRP-concrete-steel double-skin tubular columns under combined axial compression and cyclic lateral loading. Eng. Struct. 2015, 99, 214-231. [CrossRef]

29. Farahi, M.; Heidarpour, A.; Zhao, X.-L.; Al-Mahaidi, R. Compressive behaviour of concrete-filled double-skin sections consisting of corrugated plates. Eng. Struct. 2016, 111, 467-477. [CrossRef]

30. Farahi, M.; Heidarpour, A.; Zhao, X.-L.; Al-Mahaidi, R. Effect of ultra-high strength steel on mitigation of non-ductile yielding of concrete-filled double-skin columns. Constr. Build. Mater. 2017, 147, 736-749. [CrossRef]

31. Nassirnia, M.; Heidarpour, A.; Zhao, X.-L.; Minkkinen, J. Innovative hollow columns comprising corrugated plates and ultra high-strength steel tubes. Thin-Walled Struct. 2016, 101, 14-25. [CrossRef]

32. Youssf, O.; Hassanli, R.; Mills, J.E. Retrofitting square columns using FRP-confined crumb rubber concrete to improve confinement efficiency. Constr. Build. Mater. 2017, 153 (Suppl. C), 146-156. [CrossRef]

33. Standards Australia. Methods of Testing Concrete-Compressive Strength Tests-Concrete, Mortar and Grout Specimens, AS 1012.9; SAI Global: Sydney, Australia, 2014.

34. Standards Australia. Methods for Sampling and Testing Aggregates, Method for Making and Curing Concrete-Compression and Indirect Tensile Test Specimens, AS1012.8.1; SAI Global: Sydney, Australia, 2014.

35. Youssf, O.; Hassanli, R.; Mills, J.E.; Elrahman, M.A. An experimental investigation of the mechanical performance and structural application of LECA-Rubcrete. Constr. Build. Mater. 2018, 175, 239-253. [CrossRef] 
36. Youssf, O.; Mills, J.E.; Hassanli, R. Assessment of the mechanical performance of crumb rubber concrete. Constr. Build. Mater. 2016, 125, 175-183. [CrossRef]

37. Neville, A.M. Properties of Concrete Book, 5th ed.; Prentice Hall: Bergen County, NJ, USA, 1996.

38. Lam, L.; Teng, J.G. Design-oriented stress-strain model for FRP-confined concrete. Constr. Build. Mater. 2003, 17, 471. [CrossRef] 